\title{
ENTIDADES DO TERCEIRO SETOR: PARTICIPAÇÃO DEMOCRÁTICA NAS PARCERIAS COM O PODER PÚBLICO
}

\author{
THIRD SECTOR ENTITIES: DEMOCRATIC PARTICIPATION IN PARTNERSHIPS
}

WITH PUBLIC AUTHORITIES

\section{Walkiria Martinez Heinrich Ferrer}

Pós-doutorado em Sociologia do Trabalho (2019), Doutorado em Educação (2001), Mestrado em Educação (1996), Graduação em Ciências Sociais (1989), docente titular do Programa de Pós-graduação em Direito da Universidade Marília. Coordenação do Núcleo Integrado de Pesquisa e Extensão - NIPEX/UNIMAR.

Ocimar Barros de Oliveira Mestrado em Direito Público pela Universidade Federal de Uberlândia - UFU (2011), graduação em Direito pela Universidade Federal de Uberlândia (1997), professor do Centro de Ensino Superior de São Gotardo - CESG.

\section{Resumo}

O presente trabalho aborda a participação democrática nas políticas públicas pelas denominadas entidades do terceiro setor, organizadas e administradas pela sociedade civil e suas relações com o Estado na implementação de atividades de interesse público e auxílio de implementação das políticas públicas. A escolha do tema reflete na importância de se analisar esta relação frente às teorias democráticas, em especial a teoria da democracia participativa, bem como os efeitos positivos e negativos oriundos desta relação. Temse por objetivo, na primeira parte do trabalho, definir e identificar as entidades que integram o terceiro setor e a importância das relações existentes entre tais entidades e o Estado, para a consolidação da democracia. $\mathrm{Na}$ segunda parte, identificar algumas atividades de utilidade pública realizadas pelas entidades do terceiro setor e relevância para a efetivação de políticas públicas. No terceiro momento, é realizada uma análise das consequências positivas e/ou negativas nas relações entre tais entidades do terceiro setor e 0 Estado. O método de abordagem utilizado é o dedutivo e o dialético, combinado com os métodos de pesquisa bibliográfico e documental. Em conclusão, percebe-se a importância da democracia participativa, no contexto de organização da sociedade civil, criando instituições capazes de ocupar o espaço público e auxiliar na tomada de decisões políticas dialogadas, dentro da concepção da teoria discursiva de Jürgen Habermas. Contudo, há que se traçar uma linha 
demarcatória visível entre Estado e entidades do terceiro setor, ante aos perigos de captura de interesses e de desvirtuamento do processo democrático que podem advir desta relação.

Palavras-chave: Democracia. Poder público. Terceiro setor.

\begin{abstract}
This paper approaches the democratic participation in public policies by the entities denominated as the third sector - which are organized and administrated by the civil society - and its relationships with the government in implementing public interest activities and helping in the application of public policies. The importance of choosing the subject reflects on the relevance of analyzing that relationship based on the democratic theories, especially the participatory democracy theory, as well as the positive and negative effects from such relation. The goal, in the first part of this study, is to define and identify the entities that constitute the third sector and the importance of the existing relations among those entities and the State for the consolidation of democracy. In the second part, the objective is to point out some utility services carried out by third sector entities and its relevance for the fulfillment of public policies. Afterwards, it has been conducted an analysis of the positive and/or negative consequences regarding the relationships among the afore mentioned entities and the State. The method of approach that has been used is deductive and the dialectic, in combination with a bibliographic and document analysis. In conclusion, there can be noticed the importance of participatory in the context of the organization of civil society, originating institutions capable of occupying the public space and assisting in the making of dialogical political decisions, within the conception of the discursive theory of Jürgen Habermas. However, it is necessary to draw a visible line of demarcation between the State and third sector entities, given the dangers of capturing interests and distorting the democratic process that may result from this relationship.
\end{abstract}

Keywords: Democracy; Public Power; Third sector.

\title{
1. CONSIDERAÇÕES INICIAIS
}

Vive-se hoje a crise da democracia representativa. A democracia no modelo oitocentista que se propagou após o advento das revoluções burguesas e consequente implantação do Estado de Direito, de viés liberal e capitalista, não mais atende à sociedade contemporânea do século XXI.

Não é fato novo que se contextualiza uma democracia cosmopolita, advinda de um inevitável processo de globalização que, não obstante, só tenha sido tratado com grande relevância após a implantação do Estado Liberal. Não se pode olvidar que a 
globalização é um movimento que vem se estruturando desde as conquistas imperialistas iniciadas na antiguidade, passando pela intensificação do comércio ao longo da Idade Média e, na Idade Moderna, com as grandes navegações, colonialismo e revolução industrial.

Todo esse contexto permitiu que se espalhasse pelo globo terrestre, em especial nas Américas e na África, a cultura e a religião ocidental, além do estilo de vida, modelo econômico e político.

Desde a Grécia Antiga as formas de governo vêm sendo estudadas por renomados filósofos, teóricos do Estado e cientistas políticos, podendo ser citados como exemplos Platão, Aristóteles e Políbio, na Grécia Antiga; Maquiavel, Montesquieu e Rousseau, na Idade Moderna; e, na Idade Contemporânea, inúmeros estudiosos como Tocqueville, Benjamin Constant, Sieyès, Stuart Mill, Schumpeter, entre outros.

A democracia não é uma forma perfeita de governo, tendo como característica ser exclusivista desde a Grécia Antiga, deixando de fora da arena de debates grupos sociais como crianças, mulheres e estrangeiros.

Mesmo em dias atuais, nos quais a mulher conquistou direitos políticos que não detinha em séculos idos, ainda se percebe um deficit considerável de participação feminina na política. E isto demonstra que, como herança de seu caráter exclusivista, a democracia possui uma preponderância de participação masculina.

Diante da apontada crise da democracia representativa, tanto o Estado como a sociedade civil organizada tiveram que criar mecanismos que evocassem uma maior participação da cidadania na discussão e decisão das políticas públicas, na persecução do interesse público e do tão propalado bem comum.

O Estado tem editado dispositivos legais, tanto constitucionais quanto infraconstitucionais, que evocam um maior aporte de participação da cidadania na arena de discussão das políticas públicas, como plebiscitos, referendos, leis de iniciativa popular, conselhos, audiências públicas, consultas públicas etc.

O presente trabalho se propõe a buscar respostas para o seguinte problema: Qual a relevância e quais os perigos da atuação das entidades do Terceiro Setor, em parceria com o Estado, para a construção de uma democracia social e participativa, frente à crise enfrentada pela democracia representativa?

A pesquisa se desenvolverá à luz da teoria discursiva do direito, de Jürgen Habermas, que constrói seu conceito de democracia a partir da participação dos 
cidadãos no processo de formação da vontade e da opinião, afirmando ser possível ampliar as condições de reconhecimento por meio do agir comunicativo, ou seja, pela prática da argumentação, que exige uma interação entre as perspectivas de todos os agentes envolvidos no processo de discussão.

A sociedade civil tem paulatinamente ocupado o espaço público via organização de entidades associativas e sem fins lucrativos, denominadas de Entidades do Terceiro Setor, destinadas a atuar na prestação de serviços sociais, assistenciais, culturais, ambientais, de saúde, entre outros, auxiliando assim o Estado em sua difícil missão de propiciar serviços públicos e que visem atingir o almejado bem comum.

As entidades da sociedade civil organizada, quando bem administradas e de comprovada reputação perante a sociedade e o poder público, são qualificadas e certificadas como entidades de interesse público, organizações da sociedade civil de interesse público, associações públicas, auferindo o direito de executar programas de políticas públicas por meio de convênios, parcerias e contratos de gestão com o Poder Público.

Tais atividades são de suma importância para o modelo democrático, pois são capazes de ajudar a reduzir um deficit de atuação do Estado, além de contribuírem na redução do "inchaço" da máquina administrativa estatal e na desburocratização da prestação de serviços relevantes para a sociedade.

Contudo, as relações entre Estado e Entidades do Terceiro Setor devem ser implementadas cum grano salis, haja vista que, apesar dos consideráveis benefícios, podem envolver malefícios, muitas vezes ocultos para a cidadania e, em outras situações facilmente detectáveis, bastando um olhar mais atento sobre aspectos objetivos e subjetivos, muitas vezes escusos, envolvidos nesta relação.

\section{CRISE DA DEMOCRACIA REPRESENTATIVA E CRESCIMENTO DO MODELO PARTICIPATIVO:}

Embora seja a modalidade mais utilizada desde a implementação do Estado Liberal, no momento que se sucede às revoluções burguesas, em especial a francesa de 1789, tida como marco inicial da Idade Contemporânea, a democracia representativa vem apresentando mazelas que demonstram uma crise instalada.

A crise de representação passa por vários problemas que exigem uma 
inovação do modelo representativo para evitar que ele entre em colapso.

Concentrar as decisões político-administrativas nas mãos de representantes, eleitos pelo voto popular, que nem sempre elevam ao patamar de prioridade os interesses do povo, é expor a perigo o processo de democratização.

Neste sentido, o posicionamento de Ocimar Barros de Oliveira é de que:

A representação do povo por um número reduzido de políticos tem um viés perverso, pois pode gerar pelo menos duas consequências indesejadas: levando os cidadãos a uma apatia pelos assuntos relativos ao Estado, bem como germinando nos representantes do povo a ideia de que são os verdadeiros representantes do poder. Isso levaria a um rompante de pessoalidade na condução do interesse público, o que facilmente geraria decisões carregadas de abuso de poder. (OLIVEIRA, 2014, p. 63).

De outro norte, percebe-se a importância da inserção de atores da sociedade civil na esfera pública por estarem mais próximos dos problemas e demandas do cidadão comum:

Neste sentido, a inserção de atores da sociedade civil na esfera pública representa uma aproximação com o mundo da vida, dado que os atores da sociedade civil - advindos de instituições não econômicas, não estatais estão mais próximos dos problemas e das demandas do cidadão comum. (MONTEIRO; DE MOURA; LACERDA, 2015, p. 167).

O legislador constituinte, se antecipando a estes problemas, dispôs no parágrafo único do art. $1^{\circ}$ da $\mathrm{CF} / 88$ que: "todo poder emana do povo, que o exerce por meio de representantes eleitos ou diretamente, nos termos desta Constituição".

Logo, se todo poder emana do povo e a República Federativa do Brasil optou por uma democracia indireta, na qual o povo exerce o poder por meio de representantes eleitos para as funções legislativa e executiva, merece destaque o fato de ter o legislador constituinte inserido o cidadão na arena de discussão das políticas públicas, naqueles casos permitidos na própria Carta Política. Eis aí o nascedouro de uma democracia que combina a democracia representativa e a participação direta, em determinadas situações. Tal previsão constitucional está em perfeita sintonia com o fato de ser o "povo" o detentor e ao mesmo tempo destinatário do poder:

A democracia representativa decorre de razões práticas, seria impossível, tal como ocorria na Grécia, convocar em praça pública, uma multidão de cidadãos para a feitura de leis. Assim, para manter a democracia com base na vontade popular, no Estado moderno a solução foi um governo democrático com bases representativas. (CARDOSO; FERRER, 2018, p. 163).

Concentrar as decisões políticas e administrativas nas pessoas de alguns 
representantes, sem a devida participação da cidadania, é expor a iminente perigo o processo de democratização da democracia, conforme leciona o constitucionalista J. J. Gomes Canotilho: "Democratizar a democracia através da participação significa, em termos gerais, intensificar a optimização das participações dos homens no processo de decisão". (CANOTILHO, 2003, p. 434)

Não se pode olvidar que concentrar as decisões políticas nas mãos de apenas alguns nos remete a uma das principais características da democracia desde suas remotas raízes na antiguidade, o caráter exclusivista, que promove exclusões por questões de gênero, raça, classe social. Sobre o caráter exclusivista da democracia, é relevante trazer a lume as palavras e Frank Cunhingham:

\begin{abstract}
Uma orientação empírica análoga motivou teóricos primariamente preocupados com o avanço e a subordinação ou exclusão disseminadas de grande número de pessoas em virtude de aspectos como sua classe, gênero, ou pertença 'racial'. A questão com a qual começam é 'quem não governa?', e eles concluem que o governo é dominado pela classe média e alta masculina de uma raça dominante da sociedade que promove interesses específicos e a exclusão de outros grupos. (CUNHINGHAM, 2009, p. 31).
\end{abstract}

Portanto, embora estudiosos da democracia frisem o caráter exclusivista da democracia, é de relevante importância ampliar os espaços de discussão, de forma a buscar a inserção da maior pluralidade de grupos sociais possível na arena de debates, naquele processo que Canotilho denominou de democratização da democracia. Incentivando, desta forma, uma maior plenitude no exercício da cidadania.

É notório que a democracia representativa, nos moldes expostos pela visão crítica de Schumpeter, ou seja, representativa, minimalista e baseada em procedimentos, não é adequada para atender as demandas da atual sociedade, informada, informatizada, conectada e que passa por um intenso e irreversível processo de globalização.

Ratificam tal pensamento Monteiro, de Moura e Lacerda:

Dado esse panorama, aprofundou-se os debates sobre a crise e os limites da democracia representativa, minimalista, baseada em procedimentos, por ela supostamente ter sido incapaz de solucionar o problema do acesso dos diversos atores sociais ao debate público e, mais ainda, não ter sido capaz de dar alternativas ao problema da exclusão e da desigualdade social. (MONTEIRO, de MOURA; LACERDA, 2015, p. 163).

Com a mencionada crise da democracia representativa, torna-se mais importante ainda o empoderamento da cidadania, no sentido de participar da arena 
de decisões políticas, seja por meio do voto, da voz, da ocupação de espaços públicos, ou mesmo da participação em movimentos, manifestações e entidades sociais com poderes de representação e com possiblidades de celebração de parcerias com o Estado.

Portanto, torna-se notório que ao lado de uma desgastada democracia representativa, faz-se necessária a abertura de espaços nos quais a sociedade possa atuar, principalmente na organização da sociedade civil, consubstanciada nas entidades do Terceiro Setor, capazes de propiciar uma participação de baixo para cima e uma relação mais próxima entre Estado e sociedade civil. ${ }^{1}$

\section{DEFINIÇÃO DE TERCEIRO SETOR}

Conforme mencionado no item anterior, o modelo da democracia representativa está em crise, não mais sendo capaz de atender as demandas cada vez maiores e mais complexas das sociedades hodiernas.

O Estado, em decorrência do aumento dos serviços prestados pelos órgãos da Administração Direta e pelas entidades da Administração indireta, principalmente no apogeu do Estado do Bem-estar Social, vem se mostrando ineficiente no atendimento dessas demandas nas áreas da saúde, educação, cultura e políticas sociais, entre outras.

Para reduzir essa defasagem no atendimento das demandas da sociedade face ao Estado, surgiu um conjunto de entidades sem finalidades lucrativas, que são denominadas de Terceiro Setor.

A existência de um Terceiro Setor pressupõe a existência do Primeiro e do Segundo Setor, que correspondem, respectivamente, ao Estado e ao mercado (iniciativa privada).

O Primeiro Setor (Estado) tem sua organização e atribuições delimitadas na Constituição Federal e na legislação infraconstitucional. É dotado de poderes, respeitando a tripartição das funções entre os poderes Legislativo, Executivo e Judiciário, segundo a proposta de Montesquieu. Para que tais poderes sejam independentes e harmônicos entre si, coibindo o abuso e pessoalidade nas tomadas

\footnotetext{
${ }^{1}$ Insta salientar que o que legitima a criação e atuação das entidades que compõem o Terceiro Setor está no fato de serem pensadas, organizadas e instituídas pela iniciativa e voluntarismo da sociedade civil organizada. De outra forma seria fácil incorrer em desvio das finalidades para as quais foram criadas, se tornando presas fáceis para a "captura" e para malversação de recursos públicos.
} 
de decisões, está previsto o mútuo controle pelo sistema de freios e contrapesos (check and balances).

O Primeiro Setor (Estado) é constituído pela Administração Direta, pela Administração Indireta e por todos os órgãos e entidades que as integram.

O Segundo Setor é o setor privado, ou seja, o Mercado, no qual as atividades estão concentradas na organização dos meios de produção para produção e circulação de bens e serviços, com vistas à obtenção e maximização de lucros.

Como forma de organização da sociedade civil e de implementação de uma democracia social e participativa que venha a atender determinadas demandas sociais, surgiu um grupo de entidades que comumente são denominadas de Terceiro Setor. ${ }^{2}$

O terceiro setor é composto por instituições privadas que exercem atividades de interesse público, que não visam lucro e que prestam serviços para a sociedade. Estas instituições são caracterizadas juridicamente como associações, fundações ou entidades religiosas e prestam serviços em diversas áreas como saúde, educação, cultura, defesa do meio ambiente, defesa de direitos etc.

O ilustre administrativista José dos Santos Carvalho Filho assim define Terceiro Setor:

Referidas entidades que, sem dúvida, se apresentam com certo hibridismo, na medida em que, sendo privadas, desempenham função pública, têm sido denominadas de entidades do terceiro setor, a indicar que não se trata nem dos entes federativos nem das pessoas que executam a administração indireta e descentralizada daqueles, mas simplesmente compõem um tertium genus, ou seja, um agrupamento de entidades responsáveis pelo desenvolvimento de novas formas de prestação de serviços públicos. Em última análise o terceiro setor resulta de iniciativas da sociedade civil, através de pessoas de atuação voluntária, associações e organizações não governamentais, para a execução de funções eminentemente sociais, sem alvejar resultados lucrativos, como as pessoas empresariais em geral. (CARVALHO FILHO, 2011, p. 326)

Vários outros autores apresentam suas definições para o que se entende por terceiro setor, embora não haja na doutrina um consenso. Nunes assim define terceiro setor:

[...] o conjunto de organizações de origem privada, dotadas de autonomia, administrativa própria e finalidade não lucrativa, cujo objetivo é promover o bem-estar social através de ações assistenciais, culturais e de promoção da cidadania. (NUNES, 2006. p. 25)

\footnotetext{
${ }^{2}$ Tais entidades recebem diversas denominações, tais como: terceiro setor, ONGs, organizações da sociedade civil, associações sem fins lucrativos, organizações voluntárias, organizações sociais.
} 
Apresentadas as linhas demarcatórias entre primeiro, segundo e terceiro setores, cumpre identificar as diversas formas jurídicas que vinculam as entidades que compõem o Terceiro Setor às políticas públicas estatais, bem como as consequências positivas ou negativas dessa aproximação entre Estado e Terceiro Setor.

\section{MARCO REGULATÓRIO DAS PARCERIAS ENTRE A ADMINISTRAÇÃO PÚBLICA E AS ORGANIZAÇÕES DA SOCIEDADE CIVIL}

Em 31/07/2104, foi sancionado o que se denominou de novo "Marco Regulatório do Terceiro Setor", a Lei 13.019/2014. ${ }^{3}$

A principal alteração efetuada pela Lei $13.019 / 2014$ foi a substituição dos convênios, utilizados anteriormente como instrumentos para estabelecer parcerias entre o Estado e as entidades do Terceiro Setor. Doravante, tais instrumentos legais (convênios) só poderão ser utilizados em relações firmadas entre instituições públicas.

A relação jurídica entre Estado e Terceiro Setor, a partir da entrada em vigor do novo Marco Regulatório, será firmada por termos de colaboração e de fomento, entretanto, continuarão existindo os termos de parceria e os contratos de gestão, celebrados com as Organizações da sociedade Civil de Interesse Público - OSCIP e as Organizações Sociais - OS, respectivamente.

Várias outras questões, não menos importantes, precisam ser destacadas nesta relação, haja vista que envolve investimentos públicos para o desenvolvimento de atividades impregnadas de relevante valor social, tais como: os limites de gastos permitidos para cada rubrica vinculada a tais atividades; a exigência de chamamento público para as entidades interessadas; tempo mínimo de existência da instituição; comprovada experiência no objeto da parceria; existência de órgãos internos de fiscalização; prestação de contas quando se utiliza recursos públicos.

A Lei 13.019/14, Marco Regulatório do Terceiro Setor, em seu art. 2º, com as alterações introduzidas pela Lei 13.204/2015, trouxe importantes definições para compreensão das organizações da sociedade civil:4

\footnotetext{
${ }^{3}$ Embora tenha recebido a designação de Marco Regulatório do Terceiro Setor, a lei não lida com todas as questões jurídicas que envolvem as entidades do Terceiro Setor.

${ }^{4} \mathrm{O}$ art. $2^{\circ}$ da Lei 13.019/14, Marco Regulatório do Terceiro Setor, traz várias e importantes definições sobre institutos que visam conferir maior segurança às parcerias entre Estado e entidades do Terceiro Setor. No presente trabalho destaca-se somente aquelas que são mais relevantes para o tema sob análise.
} 
I - São consideradas organizações da sociedade civil:

a) entidade privada sem fins lucrativos que não distribua entre os seus sócios ou associados, conselheiros, diretores, empregados, doadores ou terceiros eventuais resultados, sobras, excedentes operacionais, brutos ou líquidos, dividendos, isenções de qualquer natureza, participações ou parcelas de seu patrimônio, auferidos mediante o exercício de suas atividades, e que os aplique integralmente na consecução do respectivo objeto social, de forma imediata ou por meio da constituição de fundo patrimonial ou fundo de reserva.

b) as sociedades cooperativas previstas na Lei 9.867 de 10 de novembro de 1999; as integradas por pessoas em situação de risco ou vulnerabilidade pessoal ou social; as alcançadas por programas de ações de combate à pobreza e de geração de trabalho e renda; as voltadas para fomento, educação e capacitação de trabalhadores rurais ou capacitação de agentes de assistência técnica e extensão rural; e as capacitadas para execução de atividades ou de projetos de interesse público e de cunho social.

c) as organizações religiosas que se dediquem a atividades ou a projetos de interesse público e de cunho social distintas das destinadas a fins exclusivamente religiosos.

Uma vez delimitadas as organizações que integram o Terceiro Setor, o artigo $2^{\circ}$ traz ainda, entre seus incisos, definições importantes, dentre elas, os instrumentos que estabelecem parcerias entre Estado e Terceiro Setor:

Termo de colaboração (inc. VII): instrumento por meio do qual são formalizadas as parcerias estabelecidas pela administração pública com organizações da sociedade civil para a consecução de finalidades de interesse público e recíproco propostas pela administração pública, que envolvam transferência de recursos financeiros.

Termo de fomento (inc. VIII): instrumento por meio do qual são formalizadas as parcerias estabelecidas pela administração pública com organizações da sociedade civil para consecução de finalidades de interesse público e recíproco propostas pelas organizações da sociedade civil, que envolvam transferência de recursos financeiros.

Acordo de cooperação (inc. VIII-A): instrumento por meio do qual são formalizadas as parcerias estabelecidas pela administração pública com organizações da sociedade civil para a consecução de finalidade de interesse público e recíproco que não envolvam transferência de recursos financeiros. 
Vale ressaltar importante instrumento de democracia social previsto na Lei 13.019/14, que trata do Procedimento de Manifestação de Interesse Social, que é um instrumento por meio do qual as organizações da sociedade civil, movimentos sociais e cidadãos poderão apresentar propostas ao poder público para que este avalie a possibilidade de realização de um chamamento público, objetivando a celebração de parceria. Tal instrumento se mostra importante para a democracia social, pois a iniciativa parte da própria sociedade civil organizada ou do cidadão, ou seja, em vez de emanar de uma estrutura hierarquizada de poder, parte da própria iniciativa da cidadania.

Importante salientar que o fato da legislação ter se preocupado em delimitar instrumentos específicos para estabelecer uma relação jurídica, que permita a parceria entre Estado e Terceiro Setor, reforça o caráter da democracia social e participativa que deflui de tais parcerias.

Entretanto, traz também algumas preocupações quanto à burocratização excessiva de tais parcerias, sendo necessário encontrar o equilíbrio entre regulação e intervenção estatal e a eficiência e celeridade peculiares à iniciativa privada.

\section{ASPECTOS POSITIVOS E ASPECTOS INDESEJADOS DA PARCERIA ENTRE ESTADO E TERCEIRO SETOR}

Delimitados os aspectos democráticos que implicam numa apontada crise da democracia representativa e no relevante papel que desempenha a democracia social e participativa, especifica-se no presente estudo aquela advinda da parceria entre Estado e entidades do Terceiro Setor, passa-se então à análise de aspectos positivos e/ou negativos desta relação.

\subsection{Aspectos positivos da parceria entre Estado e Terceiro Setor}

O próprio embasamento teórico acima explicitado demonstra a importância da atuação das entidades do Terceiro Setor, pois esta atuação é capaz de contribuir no sentido de suprir omissões do Estado na efetivação dos direitos sociais.

A parceria entre Estado e Terceiro Setor é capaz de conferir maior efetividade a múltiplos direitos sociais, tais como: educação, assistência social, cultura, saúde, qualificação profissional, preservação do meio ambiente, promoção do voluntariado, 
combate à fome e à miséria, direito de minorias etc.

De outro lado, percebe-se que tais ações, capazes de influir nas políticas públicas sociais, auxiliando na persecução dos objetivos de construir uma sociedade mais livre, justa e igualitária, são construídas por iniciativa e voluntarismo dos segmentos da sociedade civil organizada. Mencionadas ações são projetadas e efetivadas primeiramente pela cidadania, num sentido inverso ao das políticas públicas estatais, que são construídas de forma hierarquizada e burocrática, muitas vezes não chegando a contento ao seu destinatário final, os cidadãos que delas necessitam.

Monteiro, de Moura e Lacerda assim se posicionam a este respeito:

Nesse sentido, a inserção dos atores da sociedade civil na esfera pública representa uma aproximação com o mundo da vida, dado que os atores da sociedade civil - advindos de instituições não econômicas, não estatais estão mais próximos dos problemas e das demandas do cidadão comum. (MONTEIRO; DE MOURA; LACERDA, 2015, p. 167).

Outro fator que demonstra a importância das atividades desenvolvidas pelas entidades do Terceiro Setor é o envolvimento que tais atividades promovem entre os cidadãos que, voluntariamente, convergem suas ideias no sentido de organizar, constituir e colocar em funcionamento tais entidades. Tal fato demonstra uma cidadania mais ativa, mais participativa e de caráter social. Haja vista que a cidadania não se esgota apenas no momento do voto, ou seja, momento em que se escolhe os representantes eleitos pelo povo. Nesse mesmo sentido, Monteiro, de Moura e Lacerda:

\begin{abstract}
Demandas por reconhecimento, redistribuição e por políticas de presença estão na pauta do dia e colocam em cheque a representação entendida como ideias compartilhadas entre representantes. Desse modo, somente a participação limitada ao momento do voto, na experiência da democracia representativa, não contempla as especificidades das atuais democracias contemporâneas. Assiste-se, dessa forma, a um processo de pluralização dos atores de representação e de diversificação do lócus onde ela é exercida, o que tem mobilizado a teoria democrática. Dentre as questões levantadas, a da representação nos espaços participativos, assim como a da inclusão de grupos sociais específicos nos processos de representação política têm garantido seu espaço na agenda democrática. (MONTEIRO; DE MOURA; LACERDA, 2015, p. 170).
\end{abstract}

Pelos motivos expostos, dada a importância do Terceiro Setor, percebe-se que o Estado deve incentivar a organização da sociedade civil, seja por meio de concessão de benefícios, seja por meio de fomento e financiamento de atividades para, desta forma, criar novos espaços de democracia social, capazes de reduzir as omissões e 
deficiências nos diversos setores de políticas públicas sociais.

\subsection{Aspectos indesejados na parceria entre Estado e Terceiro Setor}

De outro norte, alguns aspectos indesejados podem ocorrer na intensificação da relação entre Estado e Terceiro Setor no que se refere ao incentivo, fomento e financiamento de atividades que envolvam políticas públicas sociais e setoriais.

Um primeiro aspecto e que causa certa preocupação seria o fato de algumas dessas entidades do terceiro setor serem criadas por determinação de elites políticas (dirigismo político-partidário), para que possam infiltrar nelas pessoas de confiança, desnaturando a essência de tais entidades, que é serem idealizadas e organizadas por iniciativa da sociedade civil. Tal fato propicia as mais diversas formas de desvios de finalidade e de recursos que são fartamente comentados nas mais diversas mídias.

Outro fato que causa preocupação e que é empiricamente mais notado em sociedades civis menos complexas, como distritos e municípios menos populosos, é o fato de tais entidades receberem tratamento diferenciado (perseguição política) por abrigarem em seus órgãos de direção cidadãos que no cenário político são considerados de oposição e, por tal motivo, sofrerem medidas restritivas de fomento, obstáculos para celebrarem parcerias e retaliações do poder público local. Não obstante serem mais comuns em sociedades de menor contexto populacional, isto não afasta a possibilidade da prática em contextos regionais e até nacional.

Outro fato que se pode notar numa análise mais atenta das políticas públicas locais, regionais e até nacionais, é o denominado como "captura", que pode ocorrer em ambos os sentidos.

Em sociedades menos populosas e de menor complexidade o mais comum é a tentativa da captura de instituições já existentes por membros da elite política, que utilizam a estratégia de alocar em funções estratégicas das instituições do Terceiro Setor, principalmente aquelas mais relevantes e atuantes na sociedade, pessoas indicadas e que gozam da confiança dessa elite. Captura essa de natureza nitidamente partidária e antidemocrática. Neste sentido, as precisas palavras de Irene Patrícia Nohara em entrevista ao Jornal Carta Forense:

Então, para suprir os limites do modelo representativo, que ainda é importante, há a possibilidade de atuarem ou incentivarem uma atuação mais efetiva em favor daquilo que acreditam ser melhor para a sociedade por meio 
do terceiro setor. Ocorre que, sentindo essa potencial perda de espaço, os interesses partidários não raro 'capturam' o terceiro setor. É lamentável ver que muitas entidades do terceiro setor que teriam sido criadas para fins não partidários, atuam exclusivamente com base em interesses partidários, o que subverte os fins superiores que justificam a relevância do setor público não estatal. (NOHARA, 2015).

Em sociedades mais populosas e, consequentemente, de maior complexidade nas relações sociais, além da possibilidade de captura das instituições pela elite política e por interesses partidários, percebe-se a possibilidade de captura do poder público por instituições que conseguem se tornar muito poderosas e representativas perante a sociedade e o poder público.

Tais entidades, além de exercerem grande influência como centros de poder, criam estruturas poderosas em nível regional, nacional e algumas até mesmo atuando no cenário internacional. Sendo assim possuem forte influência no cenário político e podem, por diversas estratégias, conseguir nomeação de seus associados a cargos comissionados no poder público, fazer lobby em assuntos de interesse perante os poderes públicos constituídos, serem favorecidos em celebração de parcerias, dentre outras condutas que devem ser monitoradas pelos cidadãos e pelas autoridades fiscalizadoras competentes.

Outro aspecto que vem causando preocupação no que tange à efetividade do papel social dessas entidades é a regulação das parcerias celebradas entre o Poder Público e o Terceiro Setor. Embora o Marco Regulatório do Terceiro Setor traga benefícios, no sentido de definir institutos jurídicos que regulem a celebração de parceria e, até mesmo, defina a obrigatoriedade de fiscalização e de prestação de contas quando envolva a utilização de recursos públicos, por outro lado percebe-se o aumento da burocratização desta relação, cujas consequências somente serão apreciáveis ao longo do tempo.

$\mathrm{Na}$ supramencionada entrevista ao Jornal Carta Forense, Irene Patrícia Nohara, ao ser questionada sobre os impactos do Marco Regulatório do Terceiro Setor, assim se posicionou:

Ainda é cedo para avaliar os impactos da lei, isso dependerá, a meu ver, inclusive de pesquisa empírica. Contudo, já posso mencionar algumas reclamações. Ao que ouço com maior frequência entre os estudiosos do Direito Administrativo é no sentido de que, a pretexto de democratização do acesso, a lei tornou mais complexa e, de certo modo, até mais burocrática, a parceria. (NOHARA, 2015).

Outro aspecto indesejado no que tange às atividades das entidades do Terceiro 
Setor é o desvirtuamento da finalidade social (desvio de finalidade), no intuito de praticarem a malversação de recursos públicos. Oportunistas aproveitam-se da conotação filantrópica das atividades sociais prestadas por essas organizações da sociedade civil e as utilizam para encobrir desvios de verbas e prática de condutas ímprobas e repudiáveis.

Neste sentido as considerações de Irene Patrícia Nohara:

Não é o fato de o terceiro setor ter missões nobres que o torna imune aos
abusos, muito pelo contrário: é justamente nesta seara que os 'lobos em pele
de cordeiro' se aproveitam da fachada de solidariedade que o terceiro setor
inspira para praticarem os mais absurdos desvios, sobretudo no emprego de
verbas públicas que são transferidas. É o que vulgarmente se chama de
'pilantropia', isto é, sob uma atmosfera de filantropia, faz-se tudo, menos
'caridade'. Há casos de notas frias, sedes fantasmas, estratagemas criadas
tão somente para receber os recursos públicos, mas não para devolver à
sociedade civil o que se recebe em forma de atividades de relevância pública.
(NOHARA, 2015).

Estas são algumas das preocupações que rondam as atividades das entidades do Terceiro Setor, especialmente em suas relações de parceria com o Poder Público (Primeiro Setor), sem pretensão de esgotar o tema, por ser complexo e polêmico, demandando estudos mais específicos e aprofundados, inclusive com pesquisas de campo, que investiguem a prática cotidiana de organizações desta natureza.

Detectadas por qualquer cidadão, tais práticas indesejadas na administração dos projetos decorrentes das parcerias entre entidades do Terceiro Setor e Poder Público, devem ser tomadas todas as providências adequadas à espécie, podendo o cidadão lançar mão dos instrumentos de participação democrática que estão à sua disposição, tais como representação à autoridade administrativa competente, representação ao Ministério Público, reclamação, ação popular etc.

\section{CONSIDERAÇÕES FINAIS}

A democracia representativa, adotada pela maioria dos Estados contemporâneos, principalmente em decorrência do viés liberal e capitalista do mundo pós-revoluções burguesas, embora tenha sobrevivido aos séculos, chega desgastada ao século XXI.

Fazem-se necessárias adequações à democracia representativa para que atenda às demandas sociais, em uma sociedade cada vez mais populosa, complexa, conectada e globalizada.

Ante a propalada crise do modelo representativo, surgem novas formas de se 
ocupar os espaços públicos deixados pela omissão das políticas estatais. A democracia não pode se resumir a representantes eleitos em hiatos relativamente longos de tempo, havendo necessidade da criação de espaços democráticos que propiciem a inclusão de grupos historicamente excluídos da arena de debates, tais como mulheres, crianças, estrangeiros e não cidadãos.

Além do mais, a democracia nos moldes que se propõe na contemporaneidade há de conjugar o desgastado modelo representativo com uma democracia social e participativa.

Neste contexto, surgem entidades sem fins lucrativos e que desenvolvem atividades sociais de relevante interesse público. Essas entidades, quando bem administradas, voltadas para seu objeto social e de boa reputação perante a sociedade e o Poder Público, recebem certificados de utilidade pública, de organizações da sociedade civil de interesse público ou de organizações sociais.

Devido ao perfil filantrópico e solidário de tais instituições, se tornaram importantes parceiras para o desenvolvimento de políticas públicas sociais voltadas para a educação, cultura, lazer, defesa do meio ambiente, erradicação da pobreza e combate à fome, defesa de direitos das minorias, dentre outras.

Contudo, além dos aspectos positivos supramencionados, existe uma grande preocupação com os aspectos indesejados que podem defluir desta relação do Estado com o Terceiro setor.

Entre as irregularidades mais comuns já detectadas nesta relação estão: a) serem criadas por determinação e interesses de partidos políticos e elites políticas e não por iniciativa e voluntarismo popular (dirigismo político-partidário); b) sofrerem perseguições e retaliações por abrigarem em funções de direção pessoas entendidas como de oposição política; c) o fenômeno da "captura" que pode ocorrer tanto com a captura da entidade do Terceiro Setor pelos partidos políticos e até mesmo pelo Poder Público e, em sentido inverso, a captura do interesse e do Poder Público por entidades do Terceiro Setor com representativo poder econômico e social; d) a burocratização da relação entre Terceiro Setor e Poder Público, principalmente com o advento da Lei 13.019/14, Marco Regulatório do Terceiro Setor, que pode reduzir a eficiência de tais parcerias; e) abusos e desvios de finalidade social conjugados com malversação de verbas públicas.

Para que as organizações do Terceiro Setor continuem realizando seu importante trabalho na consolidação de uma democracia social e participativa, cada 
cidadão e cada autoridade competente deve desempenhar seu papel na observação e fiscalização e das parcerias celebradas entre Estado e Terceiro Setor.

Somente com o fortalecimento de uma democracia social e participativa, na qual cada pessoa, sem discriminação de gênero, de credo religioso, de raça, cor e independentemente de seu status social ou político, deva assumir com responsabilidade seu papel como cidadão na sociedade. Não apenas votando, pois esta é uma cidadania meramente parcial, mas participando das discussões e fiscalização das políticas públicas e das entidades da sociedade civil organizada. Somente com uma postura proativa será possível erigir uma verdadeira democracia, tendo o povo como origem do poder e beneficiário das políticas públicas responsáveis decorrentes deste poder.

\section{REFERÊNCIAS BIBLIOGRÁFICAS}

CANOTILHO, J. J. Gomes. Direito Constitucional. Coimbra: Almedina, 2003.

CARDOSO, Gleissa Mendonça Faria; FERRER, Walkiria Martinez Heinrich. A reforma política brasileira à luz dos institutos plebiscito e referendo: mais uma proposta à democracia. In Revista de Direitos Fundamentais \& Democracia. Curitiba, v. 23, n. 1, p. 156-185, jan./abr., de 2018.Disponivel em file://C:/Users/Usuario/Downloads/1110-3286-1-PB\%20(6).pdf. Acesso em 04 set 2018.

CARVALHO FILHO, José dos Santos. Manual de Direito Administrativo. 24. ed. Rio de Janeiro: Lumen Juris, 2011.

CUNNINGHAM, Frank. Teorias da democracia: uma introdução crítica. Tradução Delmar José Volpato Dutra. Porto Alegre: Artmed, 2009.

HABERMAS, Jürgen. Direito e democracia entre facticidade e validade. Tradução Flávio Beno Siebeneichler Vol. 1. 2. ed. Rio de Janeiro: Tempo Brasileiro, 2003.

MONTEIRO, Lorena Madruga; DE MOURA, Joana Tereza Vaz; LACERDA, Alan Daniel Freire Lacerda. Teorias da democracia e a práxis política e social brasileira: limites e possibilidades. In Sociologias. Porto Alegre, ano 17, nº 38, jan/abr 2015, p. 156-191.

NOHARA, Irene Patrícia. Terceiro Setor: aspectos polêmicos. Carta Forense. 2015. Disponível em: www.cartaforense.com.br/conteudo/entrevistas/terceiro-setoraspectos-polemicos/15510. Acesso em: 29 jul2018. 
NUNES, Andrea. Terceiro Setor: controle e fiscalização. 2. ed. São Paulo: Método, 2006.

OLIVEIRA, Ocimar Barros de. Processo administrativo e democracia

participativa: Participação do cidadão no processo administrativo: garantia do

Estado democrático de direito. Leme/SP: Editora J.H. Mizuno, 2014.

Recebido em 10/09/2018

Aprovado em 26/09/2019

Received in 10/09/2018

Approved in 26/09/2019 